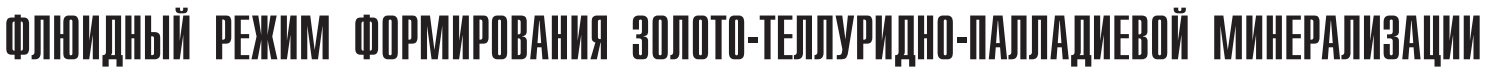

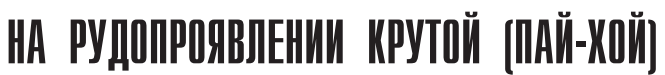

\author{
Н. В. Сокерина, Р. И. Шайбеков, С. Н. Шанина, С. И. Исаенко \\ Институт геологии Коми НЦ УрО РАН, Сыктывкар \\ sokerina@geo.komisc.ru
}

\begin{abstract}
Впервые изучены условия образования золото-теллуридно-палладиевой минерализации рудопроявления Крутой Оно приурочено к центральной части хенгурского базальтоидного комплекса и представляет собой вытянутое в северо-западном направлении пластовое тело габбродолеритов, расположенное в глинистых сланцах среднего ордовика. Золото-теллуридно-палладиевая минерализация в основном связана с зонами окварцевания крупнокристаллических габбродолеритов и кварц-халькопиритовыми прожилками. Минералообразующий флюид характеризуется очень низкой газонасыщенностью. По составу газовой фазы включения делятся на азот-метановые и углекислотно-азотные. В составе минералообразующих флюидов преобладали соли магния и кальция. Установлено, что температура образования жильного кварца близка к $300-490{ }^{\circ} \mathrm{C}$, сульфидная и связанная с ней золото-теллуридно-палладиевая минерализация образовывались при более низких температурах, не более $260{ }^{\circ} \mathrm{C}$.
\end{abstract}

Ключевые слова: золото-теллуридно-палладиевая минерализация, флюидные включения, габбродолериты, газовая хроматография, КР-спектроскопия.

\section{FLUID MODE OF GOLD-TELLURIDE-PALLADIUM MINERALIZATION FORMATION IN KRUTOY DEPOSIT (PAY-KHOY]}

\author{
N. V. Sokerina, R. I. Shaybekov, S. N. Shanina, S. I. Isaenko \\ Institute of Geology of Komi SC UB RAS, Syktyvkar
}

For the first time we studied the conditions of formation of gold-telluride-palladium mineralization in Krutoy deposit. It is confined to the central part of khengursky basalt complex. This deposit is represented by a NW elongated gabbro-dolerite body located in Middle Ordovician argillaceous shales. The gold-telluride-palladium mineralization is mainly associated with quartzchalcopyrite veins. The mineral-forming fluid is characterized by a very low gas saturation. According to the composition of the gas phase the inclusions are divided into nitrogen-methane and carbon dioxide-nitrogen. The mineral-formation fluids are dominated by magnesium and calcium salts. We determined that the formation temperature of the vein quartz was close to $300-490{ }^{\circ} \mathrm{C}$. The sulfide and associated gold-telluride mineralization was formed at lower temperatures, less than $260{ }^{\circ} \mathrm{C}$.

Keywords: gold-telluride-palladium mineralization, fluid inclusions, gabbro-dolerite, gas chromatography, Raman spectroscopy.

\section{Геологическая обстановка}

Рудопроявление Крутой выявлено Сопчинской ГПСП в 1969 году и располагается на северо-западе участка Крутой, в верхнем течении р. Хэнгоръю, и представляет собой вытянутое в северо-западном направлении пластовое тело габбродолеритов (рис. 1), согласно расположенное в глинистых сланцах среднего ордовика. Его протяженность составляет 1.5 км. По простиранию тело образует ряд раздувов и пережимов, поэтому его видимая мощность колеблется в пределах 60-200 м. Интрузив имеет юго-восточное падение под углом 60-70 .

Габбродолериты имеют отчетливо выраженное зональное строение, где в краевой части развиты мелкозернистые светло-зеленовато-серые гломерозернистые габбродолериты, сменяющиеся в центральной части крупнозернистыми кварцевыми амфиболитизированными разностями, с которыми пространственно и генетически связана зона равномерно вкрапленной ( $1-2$ мм) халькопиритпирит-пирротиновой и золото-теллуридно-палладиевой минерализации. Зона халькопирит-пирит-пирротиновой (до 20 \%) и золото-теллуридно-палладиевой минерализации прослеживается на 1.5 км, имеет мощность до 20 м и приурочена к границе среднезернистых и крупнозернистых габбродолеритов. Как правило, сульфидная минера-

лизация ассоциирует с кварц-альбитовым мирмекитом, выполняющим интерстиции между беспорядочно расположенными призматическими зернами плагиоклаза, и иногда образует прерывистые оторочки вдоль их границ. Золото-теллуридно-палладиевая минерализация приурочена как к кварц-халькопиритовым прожилкам (до 510 см), секущим крупнокристаллические габбродолериты, так и к зонам их окварцевания [3, 4, 9]. Максимальные концентрации золота и палладия по результатам анализа небольшого количества штуфных и пунктирно-бороздовых проб, отобранных непосредственно из оруденелых габбродолеритов пробирно-атомно-абсорбционным методом, составляют 0.5 и 0.05 г/т соответственно [4]. Минеральные формы золото-теллуридно-палладиевой минерализации были установлены сравнительно недавно и представлены самородным золотом, колорадоитом [9], алтаитом медистым и палладистым золотом (неопубликованные данные).

Данная статья посвящена изучению условий образования нового типа золото-теллуридно-палладиевой минерализации, локализованной в зонах окварцевания крупнокристаллических габбродолеритов, и в золотоносных кварц-халькопиритовых прожилках, их секущих. 


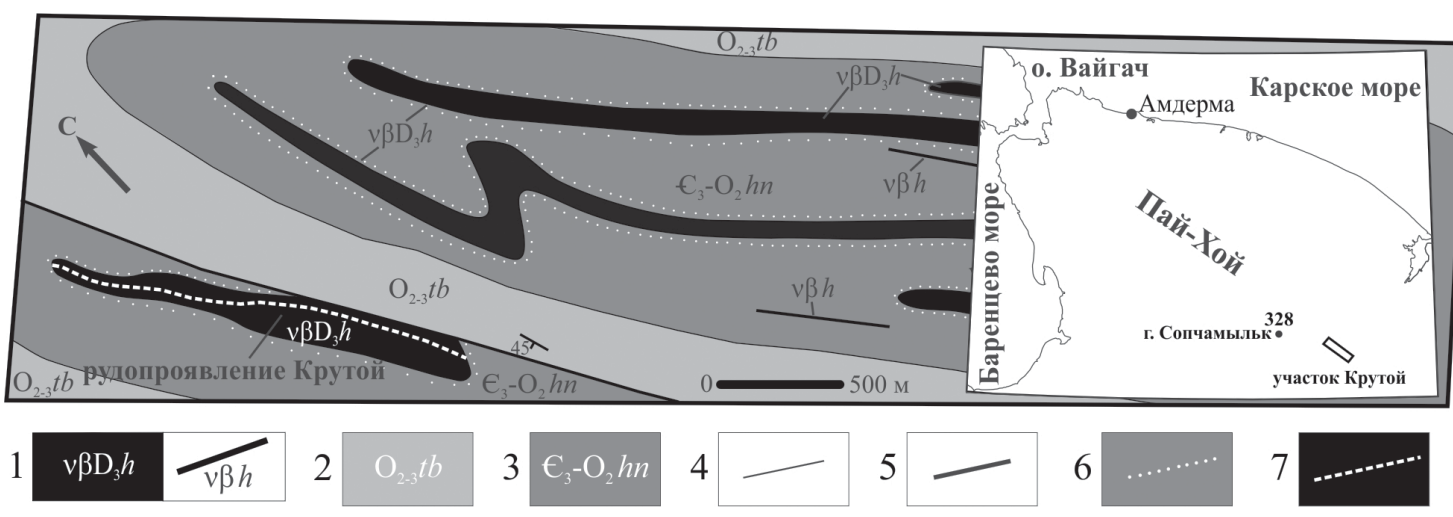

Рис. 1. Геологическая карта участка Крутой (Зархидзе и др., 2010) с дополнениями. Условные обозначения: 1 - хенгурский (центрально-пай-хойский) габбродолеритовый комплекс: габбродолериты, пикродолериты, долериты; 2 - тальбейтывисская свита: известковистые песчаники, алевролиты, песчанистые известняки, кремнисто-глинистые сланцы, локально - базальты, туфолавы; 3 - хенгурская свита: сланцы - глинисто-кремнистые, кремнисто-глинистые и их углеродистые разности, известняки, локально - базальты, туфолавы, песчаники, алевролиты, гравелиты, конгломераты, алевросланцы и углеродисто-глинистые сланцы; 4 - геологические границы; 5 - разрывные нарушения; 6 - контактовые роговики; 7 - зона золотоносной кварц-сульфидной минерализации (предполагаемая)

Fig. 1. Geological map of Krutoy site (Zarhidze et al., 2010) as amended. Legend: 1 - khengursky (Central Pay-Khoy) gabbrodolerite complex: gabbrodolerites, pikrodolerites, dolerites; 2 - talbeytyvisskaya suite: calcareous sandstones, aleurolites, sandy limestones, siliceous shales, locally — basalts, tuff lavas; 3 - khengurskaya suite: shales - clay-siliceous, siliceous-clay and their carbonaceous varieties, limestones, locally basalts, tuff lavas, sandstones, aleurolites, gravelites, conglomerates,aleuroshales and carbonaceous shales; 4 - geological boundaries; 5 - faults; 6 - contact hornfels; 7 - zone of gold-bearing quartz-sulphide mineralization (estimated)

\section{Методы исследования}

Изучение флюидных включений в жильном кварце проводилось в двуполированных пластинах методами гомогенизации и криометрии с использованием термокриостолика THMSG600 фирмы Linkam, позволяющего проводить измерения при температурах от -196 до $600{ }^{\circ} \mathrm{C}$.

Методом КР-спектроскопии оценивался состав газовой фазы отдельных включений (спектрометр LabRamHR800 HoribaJobinYvon). Спектры снимались при комнатной температуре, для их регистрации задействовалась решетка спектрометра 600 ш/мм, размер конфокального отверстия составлял 300 , щель - 100 мкм, мощность возбуждающего излучения $\mathrm{Ar}^{+}$-лазера - 120 мВт (514.5 нм).

Валовый состав газов включений был проанализирован на газовом хроматографе «Цвет-800» с приставкой для термического вскрытия включений. Для анализа использовались навески кварца массой 0.5 г фракции 0.25-0.5 мм. Вскрытие включений производилось при температурах $500,600,800$ и $1000{ }^{\circ} \mathrm{C}$. Нагрев образцов проводился в реакторе в атмосфере гелия. Чувствительность метода [6] по основным компонентам составила (мкл): $2 \cdot 10^{-2}$ для $\mathrm{N}_{2}$ и $\mathrm{CO} ; 3 \cdot 10^{-2}$ - для $\mathrm{CH}_{4}$ и $\mathrm{CO}_{2} ; 3 \cdot 10^{-3}$ - для $\mathrm{H}_{2} \mathrm{O}$.

\section{Результаты исследования и их обсуждение}

Для определения условий образования жильного кварца и связанной с ним рудной минерализации были изучены флюидные включения в жильном кварце, которые были разделены на две основные группы. Наиболее высокотемпературные включения, вероятнее всего, соответствуют стадии образования жильного кварца. Они расположены поодиночке или небольшими группами, что позволяет отнести их к первичным. Температура гомогенизации таких включений $300-490^{\circ} \mathrm{C}$, объем газовой фазы 30-60 об. \% (рис. 2, а). Температура эвтектики жидкой фазы $\left(-41,-48,-60{ }^{\circ} \mathrm{C}\right)$ свидетельствует о том, что в составе водной фазы включений присутствуют хлориды маг- ния, и кальция [2]. Соленость растворов довольно высокая: $13.5-23.5$ мас. \%, $\mathrm{NaCl}$ экв.

В местах скопления сульфидов наблюдаются более низкотемпературные включения, которые, вероятно, соответствуют времени формирования сульфидной и связанной с ней золото-теллуридно-палладиевой минерализации. Включения имеют разнообразную форму, размер обычно не превышает 20 мкм. Температура гомогенизации таких включений $134-193{ }^{\circ} \mathrm{C}$, иногда до $260{ }^{\circ} \mathrm{C}$. Объем газовой фазы не превышает 20 об. \% (рис. 2, б, в). Температура эвтектики $-34,-40,-41^{\circ} \mathrm{C}$, что свидетельствует о том, что в составе водной фазы включений присутствуют хлориды магния, вероятно с примесью солей кальция. Соленость растворов 5.5-10 мас. \%, $\mathrm{NaCl}$ экв. Они встречаются в трещинах, в небольших группах или имеют площадное распространение, что позволяет отнести их к первично-вторичным включениям.

В кварце много водных однофазовых включений (рис. 2, г).

Полученные данные, вероятно, свидетельствуют о том, что температура образования жильного кварца близка к 300-490 ${ }^{\circ} \mathrm{C}$, а сульфидная и связанная с ней золототеллуридно-палладиевая минерализация, скорее всего, образовывались при более низких температурах - не более $260{ }^{\circ} \mathrm{C}$. Наблюдается изменчивость солевого состава включений, которая выражается в довольно значительном диапазоне температур эвтектики (от -34 до $\left.60{ }^{\circ} \mathrm{C}\right)$, которые наравне с присутствием в парагенезисе с кварцем тремолита $\left(\mathrm{Ca}_{2} \mathrm{Mg}_{5}(\mathrm{OH})_{2}\left[\mathrm{Si}_{4} \mathrm{O}_{11}\right]\right)$ соответствуют предположению о кальций-магниевом составе флюида.

Газовый состав отдельных включений был изучен методом КР-спектроскопии (рис. 3, 4). Установлено, что обычно в газовой фазе преобладают метан или азот, углекислый газ встречается редко. Во включениях, содержащих углекислый газ, метан, как правило, отсутствует (рис. 4). По газовому составу нами выделены азот-мета- 

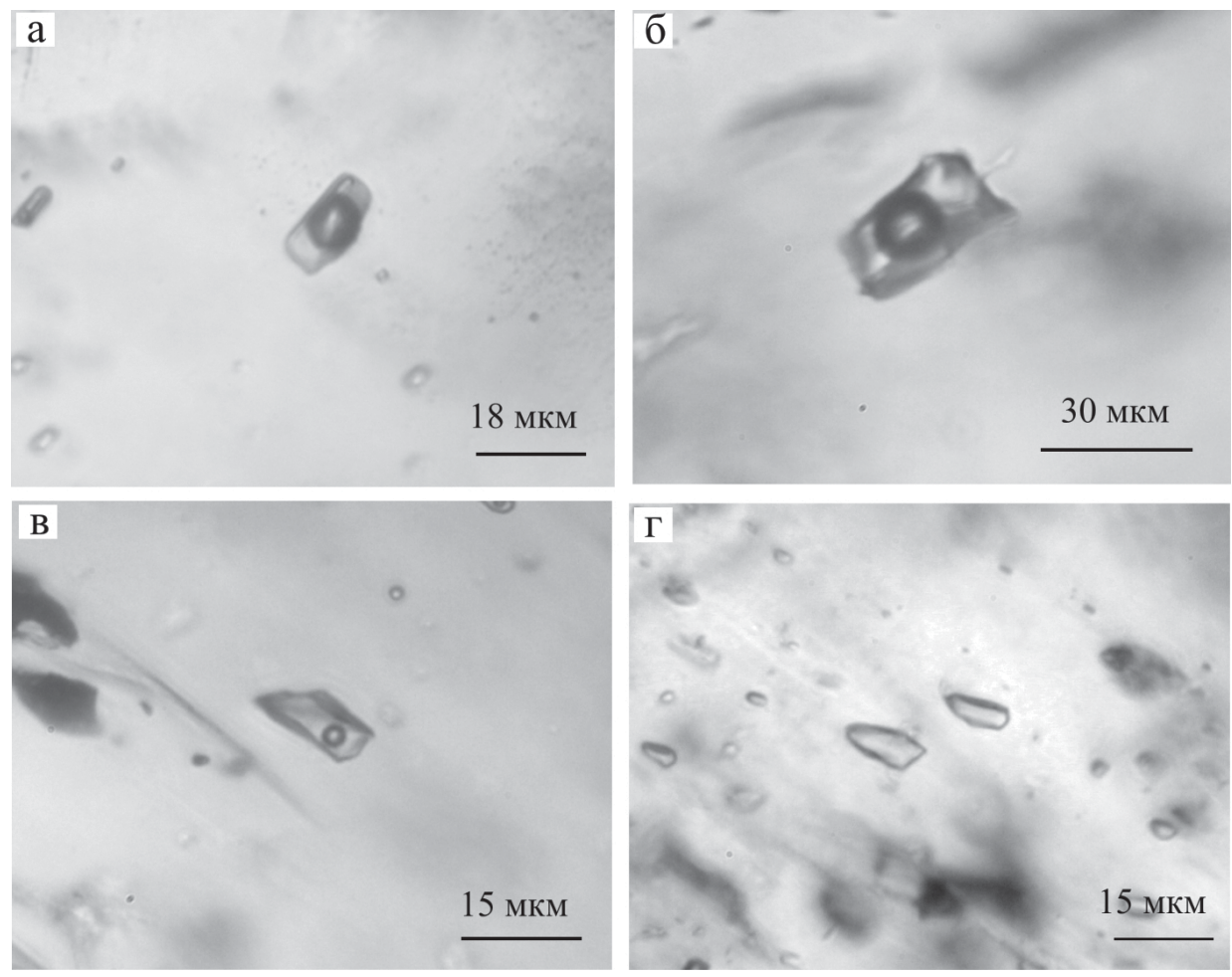

Рис. 2. Типичные флюидные включения: $а$ - с газовой фазой 60 об. \%; б - с газовой фазой около 30 об. \%; в - с газовой фазой около 5 об. \%; г - водные включения

Fig. 2. Typical fluid inclusions: a - with gas phase of 60 vol. $\%$; 6 - with gas phase 30 vol. \%; в - with gas phase about 5 vol. \%; г - water inclusions

новые и углекислотно-азотные включения. Это свидетельствует о двух источниках газов, которые могут иметь мантийное, коровое или смешанное происхождение. Проблема происхождения газов обсуждалась в многочисленных работах $[1,5,7,8,10]$. Многие авторы отмечали присутствие в магматических породах газов, типичных для метаморфогенно-осадочных толщ. В работе [7] отмечено присутствие метана в составе флюидных обособлений расплавных включений в кварце гранитов и пегматитов олово-вольфрамового месторождения. Значительные количества метана и других углеводородных газов зафиксированы в минералах пород щелочного состава
[1]. При исследовании современных термальных источников [10] обнаружены значительные количества метана (до 1.5 об. \%). Наиболее часто в постмагматических кварцевых жилах встречаются включения, в газовой фазе которых преобладает углекислый газ [5, 8 и др.]. Изученные нами кварцевые жилы расположены в магматической породе и, вероятнее всего, наследуют газовую составляющую минералообразующего флюида, отделившегося при дегазации магмы.

При изучении валового состава флюидных включений методом газовой хроматографии установлено, что газонасыщенность породы очень незначительна (см.
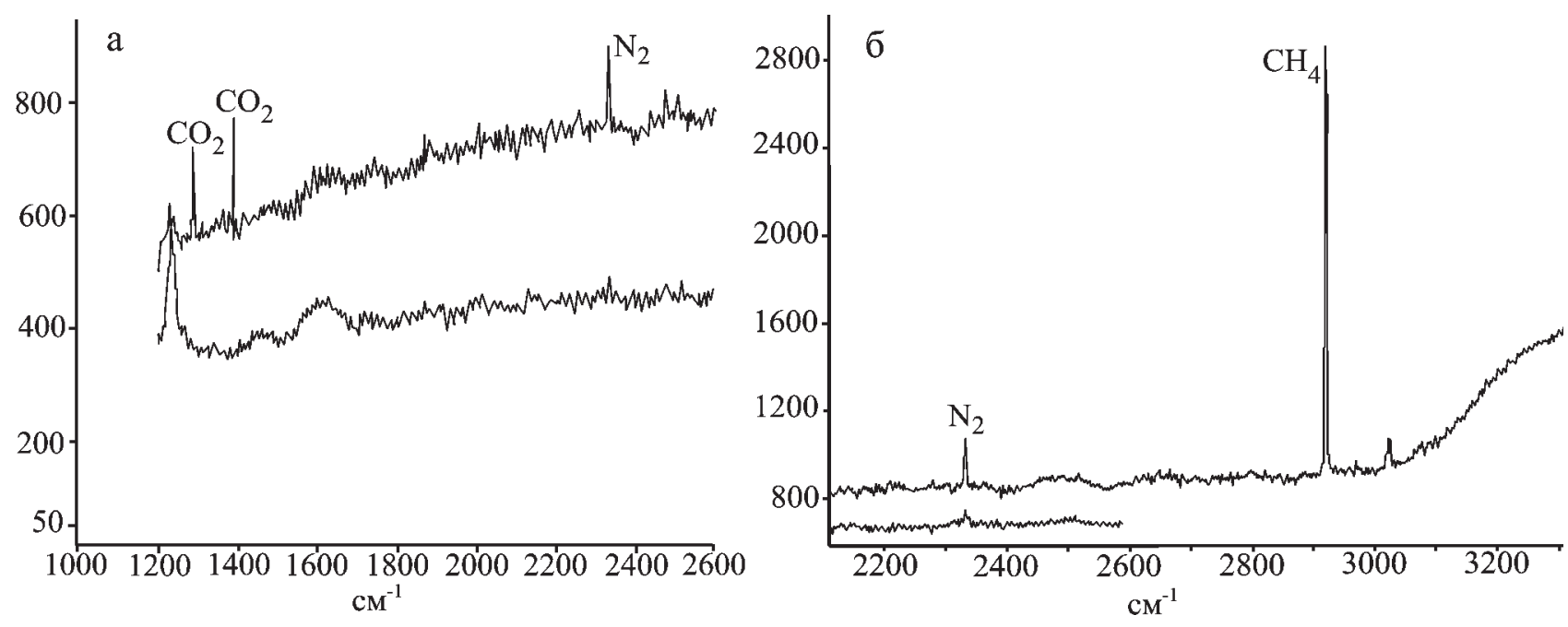

Рис. 3. КР-спектры газовой фазы включений: a - углекислотно-азотного, б - метаново-азотного составов

Fig. 3. Raman spectra of gas phase of the inclusions: a - carbonic acid - nitrogen, $\sigma-$ methane-nitrogen compositions 
таблицу) и в основном включения содержат воду (около 99 \%), что хорошо согласуется с визуальными наблюдениями. Среди газовых компонентов преобладает углекислый газ, в меньших количествах присутствуют метан и азот. Причем при стандартном нагреве кварца до $500{ }^{\circ} \mathrm{C}$ азот не обнаружен. Его выделение, так же как и основной части метана, наблюдается в интервале температур 500-800 ${ }^{\circ} \mathrm{C}$. Учитывая, что при КР-исследованиях присутствие азота и метана в составе включений было четко установлено, мы предполагаем, что эти газы принадлежат флюидным включениям, а не являются результатом разложения органического вещества при нагревании образца.

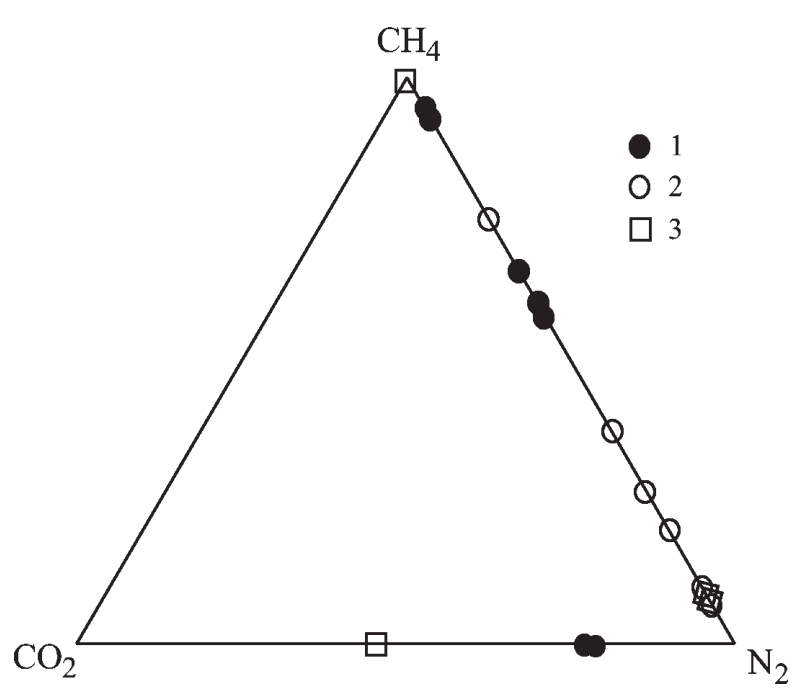

Рис. 4. Состав газов во включениях, по данным КР-спектроскопии: 1 - ГФ 3060 об. \%, 2 - ГФ 10-20 об. \%; 3 - ГФ менее 10 об. \%

Fig. 4. Composition of gases in the inclusions according to Raman spectroscopy: $1-$ gas phase about $30-60$ vol. $\%, 2-$ gas phase $10-20$ vol. $\%$; 3 - gas phase less than 10 vol. $\%$

\section{Выводы}

Образование золото-теллуридно-палладиевой минерализации на рудопроявлении Крутой соответствует представлениям о гидротермальном этапе минералообразования, когда на заключительных стадиях происходила концентрация рудных компонентов, которые после отделения флюида приняли участие в образовании постмагматической гидротермальной минерализации. Установлено, что температура образования жильного кварца близка к 300$490{ }^{\circ} \mathrm{C}$, а сульфидная и связанная с ней золото-теллуриднопалладиевая минерализация образовались при более низких температурах - не более $260^{\circ} \mathrm{C}$. В составе флюидного раствора также присутствовали соли магния и кальция, избыток которых привел к формированию в жильном кварце нитевидных кристаллов тремолита. Минералообразующий флюид отличался очень низкой газонасыщенностью, газовый состав, вероятнее всего, также был унаследован от магмы, из которой кристаллизовались габбродолериты.

Исследования проведены на базе Центра коллективного пользования «Геонаука» при частичной финансовой поддержке Программы УрО РАН № 15-18-5-46.

\section{Валовый состав газов флюидных включений в кварце} Gas composition of fluid inclusions in quartz

\begin{tabular}{c|c|c|c|c|c}
\hline \multirow{2}{*}{ № } & Т нагрева, ${ }^{\circ} \mathrm{C}$ & $\mathrm{N}_{2}$ & $\mathrm{CO}_{2}$ & $\mathrm{H}_{2} \mathrm{O}$ & $\mathrm{CH}_{4}$ \\
\cline { 3 - 6 } & T heating, ${ }^{\circ} \mathrm{C}$ & \multicolumn{4}{|c}{ мКг/г $(\mathrm{mcg} / \mathrm{g})$} \\
\hline 1a & $100-500$ & 0.00 & 4.45 & 354 & 0.108 \\
\hline 1a-1 & $100-500$ & 0.00 & 4.15 & 336 & 0.108 \\
\hline 1a-2 & $100-500$ & 0.00 & 4.43 & 332 & 0.108 \\
\hline$-/ /-$ & $500-600$ & 1.87 & 2.00 & 22 & 0.334 \\
\hline$-/ /-$ & $600-800$ & 0.47 & 6.37 & 98 & 0.6 \\
\hline$-/ /-$ & $800-1000$ & 0.00 & 0.36 & 0 & 0.002
\end{tabular}

\section{Литература}

1. Бакуменко И. Т., Томиленко А. А., Базарова Т. Ю., Ярмолюк В. В. Об условиях формирования вулканитов Западно-Забайкальской позднемезозойской-кайнозойской области [Бурятия]: (По данным изуч. расплав. и флюид. включений в минералах)// Геохимия. 1999. № 12. С. 13521356.

2. Борисенко А. С. Изучение солевого состава растворов газово-жидких включений в минералах методом криометрии // Геология и геофизика. 1977 (8). С. 16-27.

3. Жуков Ю. В., Заборин О. В., Костюкова Л. А. и др. Геологическое строение листов R-41-115-A, Б; R-41-116A, Б. (Отчет Сопчинской ГПСП по результатам геологопоисково-съемочных работ м-ба 1:50000 за 1966-1968 гг.). Воркута, 1969. 261 с. Коми ТГФ.

4. Зархидзе Д. В. Геологическое доизучение масштаба 1:200000 листов R-41-XXVIII-XXIX (Карская площадь).

5. Зыкин Н. Н., Сокерина Н. В. Генезис вод гидротермальных месторождений Приполярного Урала // Вестник ИГ Коми НЦ УрО РАН. 2015. № 9. С. 18-23.

6. Миронова О. Ф., Наумов В. Б., Салазкин А. Н. Азот в минералообразующих флюидах: Газохроматографическое определение при исследовании включений в минералах // Геохимия. 1992. № 7. С. 979-991.

7. Смирнов С. З., Бортников Н. С., Гоневчук Г. Н., Гореликова H. В. Составы расплавов и флюидный режим кристаллизации редкометалльных гранитов и пегматитов Тигриного Sn-W-месторождения (Приморье) // Доклады Академии наук. 2014. Т. 456. № 1. С. 95-100.

8. Сокерина Н. В., Шанина С. Н., Зыкин Н. Н., Исаенко C. И., Пискунова Н. Н. Условия формирования золоторудной минерализации на проявлении Синильга, Приполярный Урал (по данным изучения флюидных включений) // ЗРМО. 2013. № 6. С. 89-105.

9. Шайбеков Р. И. Золото-теллуридная минерализация в кварц-сульфидных прожилках рудопроявления участка «Крутой» (Пай-Хой) // Вестник Института геологии Коми НЦ УрО РАН. 2013. № (223). С. 13-16.

10. Mazzini A., Svensen H., Etiope G., Onderdonk N., Banks D.: Fluid origin, gas fluxes and plumbing system in the sediment-hosted Salton Sea Geothermal System (California, USA) // VolcanolGeotherm Res 2011, V. 205. 67-83.

\section{References}

1. Bakumenko I. T., Tomilenko A. A., Bazarova T. Iu., Yarmoliuk V. V. Ob usloviiakh formirovaniia vulkanitov Zapadno-Zabaikalskoi pozdnemezozoiskoi-kainozoiskoi oblasti [Buriatiia]: (Po dannym izuch. rasplav. ifliuid. vcliuchenii v mineralakh) 
(Conditions of formation of volcanites of Western-Peribaikalian Late Mesozoic-Cenozoic area (Buryatia): according to study of melts and fluid inclusions in minerals). Geohimiia, 1999, No. 12, pp. 1352-1356.

2. Borisenko A. S. Izuchenie solevogo sostava rastvorov gazovozhidkikh vcliuchenii v mineralakh metodom kriometrii (Study of salt composition of solutions of gas-fluid inclusions in minerals by cryometry). Geologiia i geofizika. 1977 (8), pp. 16-27.

3. Zhukov Yu. V., Zaborin O. V., Kostyukova L. A. et al. Geologicheskoe stroenie listov R-41-115-A, B; R-41-116-A, B (Geological structure of sheets R-41-115-A, B; R-41-116-A, B). Vorkuta, 1969, 261 pp. Komi TGF.

4. Zarhidze D. V. Geologicheskoe doizuchenie masshtaba 1:200000 (Geological study of scale 1:200000) (Kara).

5. Zykin N. N., Sokerina N. V. Genezis vod gidrotermalnykh mestorozhdenii Pripoliarnogo Urala (Genesis of waters of hydrothermal deposits of Subpolar Urals). Vestnik IG Komi SC UB RAS, 2015, No. 9, pp. 18-23.

6. Mironova O. F., Naumov V. B., Salazkin A. N. Azotv mineraloobrazuiushchikhfliuidakh: Gazokhromatograficheskoe opredelenie pri issledovanii vcliuchenii v mineralakh (Nitrogen in mineral-forming fluids: Gas chromatographical determination at study of inclusions in minerals). Geohimiia. 1992, No. 7, pp. 979-991.
7. Smirnov S. Z., Bortneykov N. S., Gonevchuk G. N., Gorelikova N. V. Sostavy rasplavov i fliuidny rezhim kristallizatcii redkometallnykh granitov i pegmatitov Tigrinogo $S n$ - $W$-mestorozhdeniia (Primore) (Compositions of melts and fluid mode of crystallization of rare metal granites andpegmatites of Tigrinoe Sn-W deposit (Far East). Doclady Akademii nauk. 2014, V. 456, No. 1, pp. 95-100.

8. Sokerina N. V., Shanina S. N., Zykin N. N., Isaenko S. I., Piskunova N. N. Usloviia formirovaniia zolotorudnoi mineralizatcii na proiavlenii Sinilga, Pripoliarny Ural (po dannym izucheniia fliuidnykh vcliuchenii) (Conditions of formation of gold mineralization in Silniga occurrence, Subpolar Urals (according to study of fluid inclusions). ZRMO, 2013, No. 6, pp. 89105.

9. Shaybekov R. I. Zoloto-telluridnaia mineralizatciia v kvartc-sulfidnykh prozhilkakh rudoproiavleniia uchastka «Krutoi» (Pai-Hoi) (Gold-telluride mineralization in quartz-sulphide veinlets of Kritoy Site(Pay-Khoy)). Vestnik of Institute of Geology KomiSC UB RAS. 2013, No. (223), pp. 13-16.

10. Mazzini A., Svensen H., Etiope G., Onderdonk N., Banks D.: Fluid origin, gas fluxes and plumbing system in the sediment-hosted Salton Sea Geothermal System (California, USA). VolcanolGeotherm Res 2011, V. 205, pp. 67-83. 